\title{
A STUDY OF GREEN HUMAN RESOURCES MANAGEMENT (GHRM) AND GREEN CREATIVITY FOR HUMAN RESOURCES PROFESSIONALS
}

\author{
Md. Chapol Ali \\ Research Fellow \\ Department of Business Administration \\ Wonkwang University, South Korea \\ E-mail: chapol1344@gmail.com \\ K. M. Anwarul Islam \\ Associate Professor \\ Department of Business Administration \\ The Millennium University, Dhaka, Bangladesh \\ PhD Candidate \\ University of Selangor, Malaysia \\ E-mail: ai419bankingdu@ gmail.com \\ Dr. Soo-Jin Chung \\ Professor \\ Department of Business Administration \\ Wonkwang University, South Korea \\ E-mail: sj@wku.ac.kr (Corresponding Author) \\ Nurul Mohammad Zayed \\ Assistant Professor and Head \\ Department of Real Estate \\ Daffodil International University, Dhaka, Bangladesh \\ E-mail: Zayed.bba@daffodilvarsity.edu.bd

\section{Mithila Afrin} \\ Lecturer \\ Department of English \\ East Delta University, Chattogram, Bangladesh \\ E-mail: mithila.a@eastdelta.edu.bd
}

\begin{abstract}
The concept of green human resource management has recently combined with ecological management in business, urbanization, industrialization and so many so forth. It is mainly responsible for managing human resources work, and these work conditions are good. Green human resource management procedures are fundamentally used to reduce the carbon impression of each worker and the information capital of the holding association. It also plays
\end{abstract}


role in convincing workers to look after resources, and participate in waste management to control pollution. It is recommended that companies should be more aware of each of the capabilities that make human resources management green. The development needs of combining ecological manageability with human resource management. Organizations now recognize that while focusing on money-related benefits, they should think about the social and ecological effects to ensure their manageability. Therefore, this notion has lately taken into account, academic analysts and experts. This paper investigates GHRM practices in organizations based on the many current writings. The study found the importance of GHRM ideas, practices, strategies, and difficulties in the business and other organizations. The study uses documented strategies to observe, collect and dissipate contemporary surveys of green human resource management.

Keywords: GHRM, Human Resources Management, Environment, Sustainability, Green Creativity, Professionals.

\section{INTRODUCTION}

The development world concerns about the conditions forces companies to move to maintainable activities and elaborate on green methods. The global benchmark for conservation and protection requires companies to design conditional systems. For everyone "green human resource management" is becoming a huge management area (Mehta \& Chugan, 2015). Integrating natural destinations and procedures into an organization's overall key advancement goals helps to reach a successful environmental management framework. Fayyazia, Shahbazmoradib, Afsharc, and Shahbazmoradic (2015) says ecological management in human resource management (HRM) The fusion has a prerequisite because it is basic or important, not a simple temptation.

Due to the development of global natural concerns and the improvement of global natural models, organizations need to accept formal ecological practices (Daily \& Huang, 2001). Different types of writing about green marketing (Peattie \& Ratnayaka, 1992), Green Retailing (Kee-hung, 2010), Green Bookkeeping (Bebbington, 2001), and green management, but has focused the concept of green human resource management (GHRM). Analysts believe that accepting ecological practices is a key driver behind organizational work because the quality of human resource management practices has made them huge. Lee (2009) defines "green management" as an activity, and the organization has established a natural management approach to the planet.

The contribution and interest of employees and the association of workers are fundamental to the realization of the concept of "green human resource management". We need to implement this practice in our daily lives (Renwick, Redman, \& Maguire, 2008). They have shown that natural management frameworks can have an optimistic impact on the character or ecological thinking and behavior of workers' private lives.

The vulnerabilities contain guidance on well-known literature, its extent and inclusiveness, as well as procedural models and research motives in the field. We are aware that HR professionals are having an in-depth discussion on the term "green human resource management". Currently, organizations are focusing on integrating natural maintainability into their HR technologies. As needed, a large amount of research is being carried out to rationalize the green human resource management. This study might help HR professionals for the implementation of green human resources management system. It might also support employees 
to embrace green management strategies to protect and enhance the prosperity of organizations. Further research might find the new findings and information on this regards.

\section{METHODOLOGY}

This is subjective research and depends on extensive surveys of existing parts of the Green Human Resources Management literature. Document auditing is accepted because it helps to build research and information in the field (Tranfield, Denyer, \& Smart 2003). Survey objectives, the use of real strategies led to accurate auditing of the literature. Different information wells contain books, diaries, e-paper and websites. Current research papers are necessary to investigate current literature. According to management organizations, GHRM emphasizes opportunities for environmental management. A detailed and effective investigation was conducted on the collected documents.

\section{LITERATURE REVIEW}

The Western literature is largely followed by green human resource management. Fayyazia, Shahbazmoradib, Afsharc, and Shahbazmoradic (2015) stated human resource management (HRM) is like environmental management than simple temptation. It is necessary to merge them. Special efforts require for effective environmental management in human resource management of an organization (Rothenberg, 2003). Basically, to help the entire implementation and protection of the environmental management frameworks in the organization require human resource practices.

Supportability within the HR administrators can quickly adjust with the organization to select environmental heroes. An experimental research is characterized by environmental management practices that perform organizational performance using various parameters.

Important insights recognize the coordination of environmental destinations and methods, as well as the organization's key improvement goals, have led to a viable environmental management framework. Day after day and Huang (2001) suggest that organizations basically need to adjust mechanical development, just as they protect the environment, because it has been confirmed that by adopting green practices, organizations may benefit more than before (Murari \& Bhandari, 2011).

The HR department has made a significant contribution to the organization's supportive culture formation (Harmon, 2010). It is recognized that the more important the quality of green human resources is, the more notable is the power of organizations to choose environmental management frameworks (EMS) and arrangements. Different contemporary researchers have recently strengthened their understanding and focus on green human resource management (Berrone \& Gomez-Mejia, 2009).

Integration of technology and environmental aims into the organizations largely important improvement goals help to reach a viable EMS foundation (Haden, Oyler, \& Humphreys, 2009). Different scientists support human resource management practices to promote the development of human capital and bring customers who give organizational execution and advantages (Boselie, Paauwe, \& Jansen, 2001). Recognized strategies for registration, execution and evaluation management, preparation and workforce improvement, employee relations and rewards frameworks are seen as useful assets for adjusting employees' organizational environmental approaches (Renwick et al., 2008). Some experts believe that in order to achieve a viable corporate green management framework, many professional and managerial competencies must be promoted among the employees (Daily, Bishop, \& Steiner, 
2007). Others believe of the organization is improving. Imaginative tools and environmental management activities (EM) will make a difference, which will fundamentally affect the company's supportability and enhance its advantages (Lin, Jones, \& Hsieh).

In this way, in order to expand such a structure, it ultimately has a convincing human resources management effort, including the introduction of strict enrollment methods (Grolleau, Mzoughi, \& Pekovic, 2012). It encourages new capabilities and skills among the professionals of the "Pro Green" organization. So, no matter what strategy they use to conduct research, these analysts have advanced the concepts that are important to the legal arrangement of human resource management standards, as well as the green management objectives in the organization.

Fundamentally, Green Human Resource Management, which, as pointed out by Dutta (2012), contains two notable components, particularly environmentally friendly human resource practices and the protection of learning capital. Because it implies direct use of each worker's contact/interface to advance viable practices and increase employee mindfulness and accountability for supportability issues (Mandip, 2012). The organization's human resources department undertakes noteworthy effort to place environmental responsibility as part of the company's target statement. So workers can continue to use such an example in their private lives.

The main goal of green HR management is to alert employees to the complexity of environmental management, such as what activities are needed, how they are capable, and how they can help the environment. This activity really promotes the work of workers and is proud of their great step towards becoming an environmentally friendly program. Cherian and Jacob (2012) distributed a comprehensive outline focusing on green human resource management. It should be recognized that supportability, integration of native habitats and human resource management is a new area for rapid improvement, and therefore, the various works created entirely are not described.

Green Human Resource Management has mentioned each exercise that involves promoting, implementing, and maintaining a framework that is used to make employees' organizations green (environmentally friendly) (Mehta \& Chugan, 2015). One of the human resource management parties is worried about turning a typical worker into a green environment, such as an environmentally-friendly employee, in order to ultimately achieve the organization's environmental goals, thereby making a huge commitment to environmental maintainability. HRM framework particularly exercises, abilities, and procedures designed to attract, create, and maintain (or discard) the company's human resources. It implies personal management strategies and practices for concerns about the broader corporate environmental agenda.

To be honest, it implies strategies, practices, and frameworks that green the organization's staff to assist individuals, society, conventional habitats, and businesses (Opatha \& Arulrajah, 2014). The motivation behind green human resource management is to develop, upgrade, and maintain greening among every employee in the organization. The goal is for the person to give the most extreme personal commitment to each of the four jobs, namely, protectionist, medium, and non- polluter and creator. In these respects, it is seen as an approach to organize green development to ensure environmental security. Green HR Management places great emphasis on nurturing a green workforce, understanding, recognizing and practicing green activities, and through human resource management processes, including recruiting, procuring, preparing, correcting, creating and promoting organizational human capital, maintaining its green goals ( Mathapati, 2013). 


\section{WHAT GREEN HUMAN RESOURCE MANAGEMENT REALLY MEANS?}

It is basically mean to use of green practices and process into the green HR professionals. It involves in obtaining human capital, accepting, preparing, executing management and rewarding management. These goals will target the overall impression of the organization. The elements of human resource management are generally considered traditional and practice multiple green approaches in all the ways.

\section{GREEN HUMAN RESOURCES PLANNING}

It means to take part in estimating the number of employees and sorts of workers, expected to actualize corporate environmental management activities or programs (for example ISO 14001, capable consideration, cleaner creation, and many more).

- Participate in some employees and workers who are expected to perform corporate environmental management activities/plans/exercise (like ISO 14001, clean creation, careful consideration, etc.).

- Participate in the selection of technologies to meet the identified needs of environmental work as selection of experts/experts for vitality or environmental review, etc. (Opatha, \& Arulrajah, 2015).

As a rule, sets of expectations can be utilized to determine the quantity of environmental security related undertaking, obligations, and duties (Renwick et al., 2013). Sets of responsibilities and individual (work) particulars incorporate with social, environmental, and individual in the organizations. For instance, insurance obligations are incorporated, alongside the assignment of environmental detailing jobs and wellbeing and security errands. Organizations may also use cooperation and cross-practical groups as employment plan procedures to effectively deal with the environmental issues.

\section{GREEN HUMAN RESOURCES RECRUITMENT}

The way reasonable procedure, environmental framework and acquainted with the expressions of protection and supportable environment. Green enrollment makes it beyond any doubt those new abilities know about the green practices and environmental framework that will bolster the powerful environmental management inside the organization (Wehrmeyer, 1996). Picking up the most inventive and creative workers, expanding the enrolling potential and enlisting quality staffs are extremely urgent. Wehrmeyer (1996) suggests the following:

- The sets of responsibilities should determine the environmental announcing job, wellbeing and security errands, and other environmental effect related jobs.

- The meeting should be customized to measure the potential similarity of the competitor with the organization's green objectives.

- The acceptance program should be intended to give newcomers data about manageable advancement strategies and duties, EMS and green objectives of the organization.

\section{GREEN ORIENTATION}

The approach, framework, and practices of corporate environmental management is for choosing the contender for the posts, the organizations should give the important orientations. In certain occasions, organizations show explicit green acceptance to their newcomers. They draft new employees about environmental direction programs explicit to their employments. Worker direction projects should be structured so as to encourage the combination of new employees into a culture of green awareness. Acceptance projects should feature an organization's anxiety for 
green issues of employees like their wellbeing, security and green working conditions (Deshwal, 2015).

\section{GREEN HUMAN RESOURCES TRAINING AND DEVELOPMENT}

Preparing and advancement programs address environmental and social issues to employees at all dimensions. Preparing and improvement comprise working strategies to diminish squander, legitimate use of resources, and preservation of vitality and lessens environmental corruption. It gives a chance to connect with workers in environmental critical thinking (Zoogah, 2011). They have completed an examination by adopting a different contextual analysis strategy and distinguished the job of Green preparing and advancement in advancing business esteem. Also, (Daily, Bishop, \& Steiner, 2007) led a study among 437 workers and the consequence of the study demonstrates that the development of a powerful green management framework was straightforwardly subject to environmental training and development.

\section{GREEN PERFORMANCE APPRAISAL SYSTEM}

Performance Management (PM) introduces the difficulties of environmental execution models that crosswise over various units and increase valuable information. Environmental targets set by the organizations are met by the green human resource management system. It is a continuous procedure among the administrators and workers. It mainly happens when the organizational targets are achieved. Green HRM incorporates with the organizational strategies and environmental obligations. It goes to secure environmental management. So, there is a linkage between green HRM and green job depiction (Mandip, 2012).

\section{GREEN LEARNING AND DEVELOPMENT PROGRAMS}

Continuous green training and development plans are combined with projects, workshops and conferences to enable employees to create and obtain information about environmental management. It also helps to grow green capabilities and mentality. The focus of work in the green task becomes a basic career improvement plan that it can be carried out by a competent green supervisor. Preparation materials are be created to expand the capabilities of employees and their learning in environmental management. They can be widely used in network and electronic modules and smart media as preparation equipment for environmental management. The health, vitality and effectiveness of the environment, waste management and reuse can become the main purpose of green management. The online course materials and situational investigations instead of relying on the free printing, thus further reduce the use of paper.

\section{GREEN COMPENSATION AND REWARD SYSTEM}

The salary part can be used to push workers to change behavior to achieve green execution (Mehta \& Chugan, 2015). Salary and reward system promise the green management. The salary package may modify based on the green capabilities and achievements (Deshwal, 2015). Monetary and non-monetary-based prizes can be used for employee green achievements. Moneybased rewards can be based on commitments to the environmental management. Salary increases, monetary incentives and types of rewards can be considered. For on-monetary rewards as holidays, special holidays, and blessings to workers and their relatives can be included. CEO or senior management will acknowledge and put extensive attention and public recognition and energy to the green efforts. 


\section{GREEN EMPLOYEE RELATIONS}

Enhancing "e-commerce visionaries" is the foundation for enhancing the capabilities of the organization's products and administrative staff, which can make full use of existing money, human and natural resources (Deshwal, 2015). Workers' interest in green activities provides better green management opportunities for adjusting employees' goals, capabilities, inspiration and observations through green management practices and frameworks. Employees including EM employees are considered to improve the EM framework, such as efficient use of resources reduction of waste reduction of pollution in the work environment. In their study, some experts believe that strengthening will definitely affect profitability and execution, and encourage restraint, reasoning and critical thinking skills (Renwick et al. 2008). An important way to increase employee contribution to an organization is to find business people with social or biological status within the organization. It is called "eco-business people" (Mandip, 2012). By this way, all employees may stimulate their enthusiasm for environmental issues and use their capabilities.

Employees in the human resources department need to put pressure on management to make it a participatory workplace, so that employees can put forward their own ideas on green issues. Because they are actually responsible for implementing ethical corporate behavior in the daily existence of the organization people. This means that the achievement of green results usually depends on the enthusiasm of employees for teamwork because usually the best ideas come from employees who work in a specific area.

\section{ELEMENTS OF AFFECTING THE GREEN HUMAN RESOURCES MANAGEMENT}

Green human resource management focuses on transforming typical workers into green workers (such as environmentally friendly employees) in order to finally achieve the environmental goals of the organization, thereby making a significant commitment to environmental manageability. Experts are particularly interested in variables related to the effective implementation of the Green HR method. The components of HRM (recruitment, determination, preparation, implementation evaluation and rewards) have distinguished the concomitant variables determined by the implementation of green human resource management techniques.

Human resource arrangements are developing rules on how to supervise individuals in the organization. They describe the organization's insights and estimation methods, and how the method should treat individuals. Human resource management methods provide a summary direction for how to deal with human resource issues (Armstrong, 2009). The work of senior management in achieving more prominent aspects of environmental execution can be confirmed from different angles. The method is to self-manage the staff, formulate innovative answers to the questions raised, establish environmental awareness, and realize their expertise in this field. Teamwork requires collective contributions and the maintainable advantage rises from the group rather than from the person. The purpose is to fundamentally show the importance of the employee association through strengthening and cooperation.

The basic components of empowering workers and their desire to make recommendations are effective for environmental management system. In order to improve employees' awareness of inclusive management, in this case, employees should not hesitate to make suggestions and urge themselves to improve. Finally, management behavior is a model for the rest of the organization. How to treat the head of the employee matters. The performance framework must reflect the great expression of environmental grandeur in advertising, planning, activities and 
administration, and mean that all employees have key responsibilities in terms of environmental quality (McLaughlin, 1993).

\section{MAIN CHALLENGES OF GREEN HUMAN RESOURCE MANAGEMENT}

Human resources undertake the important task of supervising the work of employees from entry to resignation. Currently, the company is committed to green business; therefore, the human resources office has the responsibility to practice environmental awareness together with human resources methods. The human resource strategy is developing rules on how to monitor individuals. They describe how the organization handles theories and estimates of individuals. The human resources strategy provides a summary direction for how to manage human resources.

Deshwal (2015) pointed out the difficulties associated with green human resource management.

- It is difficult to change the behavior of workers within a limited time frame.

- Not every employee is equally persuaded to be interested in the development of green human resource management practices in the organization.

- It is an awkward and long process to develop a green human resource management lifestyle throughout the organization.

- It requires high speculation at the bottom stage and a near-medium rate of return.

- Purchasing and recruiting green employees with quality gifts is a difficult task.

- It is difficult to evaluate the feasibility of green human resource management practices in the behavior of employees.

- The problem that human resources experts face is that they must rely on them to provide basic green structures, green procedures, green tools and green reasoning to make the best choice and establish the organization's future green pioneers.

\section{IMPLICATIONS}

Our discoveries give HR professionals a more profound comprehension of how to accomplish predominant green innovativeness among their employees, particularly when firms want to transform the difficulties brought by environmental issues into circumstances. To begin with, it should be understood that putting resources into environmental issues were not an exercise in futility, endeavors, resources, which expanded the weight of a firm. Interestingly, it has turned into a viable way to deal with addition upper hands by improving green innovativeness these days, which can help firms to catch new green markets. Consequently, organizations should fittingly build interest in environmental management and endeavor to set up an environmentally inviting picture to pull in similarly invested job searchers. So as to animate employees' green energy and green innovativeness, firms should make a functioning help environment, for example, giving budgetary help, presenting progressed environmental management strategies, and building up a framework that energizes workers' green imagination.

Second, organizations would need to adjust the idea of green into their long-run environmental techniques that it would require an high level arrangement of Green Human Resources Management including green preparing and advancement, green pay, and compensates, etc. The environmental procedure gives a bearing to organizations to develop green intensity and makes an environment-friendly climate, which gives the vital resources and backing to create thoughts that are helpful for the manageable advancement of the organization. Along these lines, the HR office should genuinely execute Green Human Resources 
Management practices. For instance, while selecting new employees, giving more consideration to the environmental quality and environmental consciousness of workers. Green training should not just concentrate on improving workers' environmental security aptitudes; however they should likewise endeavor to pass on the organization's environmental management objectives and qualities to the people.

Third, this investigation gives critical recommendations to chiefs utilizing transformational initiative to manage Green Human Resources Management and motivate workers' green enthusiasm. Pioneers can use transformational practices in the beginning periods of Green Human Resources Management advancement to set up standards for collaboration, green, and development and can submit a specific measure of organizational resources so as to devise eco-friendly enthusiasm and inventiveness for workers. In this way, transformational administration can improve firms' green imagination by impacting Green Human Resources Management and invigorating workers' innovativeness. This reminds specialists that so as to improve green imagination and addition green aggressiveness, firms can concentrate on encouraging transformational administration, and causing chiefs to assume a crucial job. Some administrative intercessions, for example, green group building, conceptualizing rivalries, or pay plans for expanding green innovativeness, may be great decisions.

At last, as we probably aware that China is the second biggest economy on the planet. Until the mid-21st century, undertakings have been exorbitantly seeking after financial advantages and ignoring environmental issues during the time spent advancement. In any case, with the debasement of the environment, the attention to us relating environmental insurance has steadily expanded. For example, The Chinese government is additionally effectively advancing the change of the advancement model of ventures, and encouraging undertakings to respect financial improvement, and security of the biological environment as similarly significant which may convey certain difficulties to the organizations. Through environmental management, assembling the environmental energy of workers and upgrading their green inventiveness; in any case, it is likewise feasible for organizations to transform difficulties into circumstances and increase an upper hand.

For organizations that may face similar promotions in emerging economies, our inspection can prove that their organizations have changed their financial improvement models and achieved green promotion goals. In addition, the past studies have emerged as a beneficial link between the environment, human resource management and the company. There are multiple purposes behind the organization, and it can accept the green human resource management practices within the organization. These practices will neither bring benefits to the organization, but also provide the most important resource or part of the organization that can never be ignored (ie employees) Point of contact. Green human resource management practices improve the spirit of employees, which may save the environment, which will be valuable to both the organization and the workers.

\section{CONCLUSION}

There is an innate limit of Human Resources Management. It works for greening professionals and organizations. From job starting to professional relations, Human Resources Management plays big role in greening organizational goals. HR experts comprehend green human resources management in changing their organizations. Because, it prompts the better environmental organization. Green human resources management is another marvel of Human Resources Management. Though, it may make some difficulties for HR experts. It also investigates the 
ideas, significance, procedures, necessities, and difficulties of Green Human Resources Management. So, Green HR can receive different green procedures and practices in various situations for arranging, obtaining of human capital.

Particular management approaches, professionals' duty, cooperation, strengthening positive conducts, straightforward frameworks are related to Green HR techniques. But the professionals face various difficulties with respect to Green Human Resources Management. However, professionals must address the needs of green procedures, strategies and practices in management. So, it assists the specialist with identifying the regions of Green Human Resources Management that are yet to be inquired about.

The direction of this research depends on extensive research on existing literature. The author tries to sort out the concepts, procedures, preconditions and difficulties of green human resource management in a valuable way. The purpose is to provide support for interested readers, scientists and academicians. In any case, green human resource management is an evolving reasoning. To be sure, there are still many gaps in green human resource management that need to be filled. These loopholes include guidance on new literature, its expansion and inclusion, as well as program models and research plans in the field. Hypothetical and accuracy checks are expected to increase the types of green human resource management information. Interested benefactors/experts can conduct extensive quantitative and subjective research on green human resource management.

\section{REFERENCES}

Armstrong, M. (2009). HR policies procedures and systems. Armstrong's Handbook of Human Resource Management Practice, 11th ed., 985-1015.

Bebbington, J. (2001). Sustainable development: A review of the international development, business and accounting literature. Accounting Forum, 25, 128-157.

Berrone, P., \& Gomez-Mejia, L. R. (2009). Environmental performance and executive compensation: An integrated agency-institutional perspective. Academy of Management Journal, 52(1), 103-126.

Boselie, P., Paauwe, J., \& Jansen, P. (2001). Human resource management and performance: lessons from the Netherlands. International journal of human resource management, 12(7), 1107-1125.

Cherian, J., \& Jacob, J. (2012). A study of Green HR practices and its effective implementation in the organization: A review. International Journal of Business and Management, 7, 25-33.

Daily, B. F., Bishop, J., \& Steiner, R. (2007). The mediating role of EMS teamwork as it pertains to HR factors and perceived environmental performance. Journal of Applied Business Research, 23, 95-109.

Daily, B. F., \& Huang, S. C. (2001). Achieving sustainability through attention to human resource factors in environmental management. International Journal of operations \& production management.

Deshwal, P. (2015). Green Human Resource Management: An organizational strategy of greening people. International Journal of Applied Research, 1(13), 176-181.

Dutta, S. (2012). Greening people: A strategic dimension. ZENITH: International Journal of Business Economics \& Management Research, 2, 143-148. 
Fayyazia, M., Shahbazmoradib, S., Afsharc, Z., \& Shahbazmoradic, M.R. (2015). Investigating the barriers of the green human resource management implementation in oil industry, Management Science Letters, 5, 101-108.

Grolleau, G., Mzoughi, N., \& Pekovic, S. (2012). Green not (only) for profit: An empirical examination of the effect of environmental-related standards on employees' recruitment. Resource and Energy Economics, 34(1), 74-92.

Harmon, J., Fairfield, K. D., \& Wirtenberg, J. (2010). Missing an opportunity: HR leadership and sustainability. People and strategy, 33(1), 16.

Huang, T. C. (2001). The relation of training practices and organizational performance in small and medium size enterprises. Education+ Training.

Haden, S. S. P., Oyler, J. D., \& Humphreys, J. H. (2009). Historical, practical, and theoretical perspectives on green management: An exploratory analysis. Management Decision, 47(7), 1041-1055.

Lin, B., Jones, C. A., \& Hsieh, C. T. (2001). Environmental practices and assessment: a process perspective. Industrial Management \& Data Systems.

Lee, K. (2009). Gender differences in Hong Kong adolescent consumers' green purchasing behavior. Journal of consumer marketing.

Murari, K., \& Bhandari, M. (2011). Green HR: Going green with pride. Journal of Social Welfare \& Management, 3(3-4), 35-38.

Mandip, G. (2012). Green Human Resource Management: People management commitment to environmental sustainability. Research Journal of Recent Sciences, 1, 244-252.

Mathapati, C. M. (2013). Green Human Resource Management: A strategic facet. Tactful Management Research Journal, 2(2), 1-6.

Mehta, K., \& Chugan, P. K. (2015). Green HRM in pursuit of environmentally sustainable business. Pursuit of Environmentally Sustainable Business (June 1, 2015). Universal Journal of Industrial and Business Management, 3(3), 74-81.

Opatha, H. H. P., \& Arulrajah, A. A. (2014). Green human resource management: Simplified general reflections. International Business Research, 7(8), 101.

Peattie, K., \& Ratnayaka, M. (1992). Responding to the green movement. Industrial Marketing Management, 21(2), 103-110.

Renwick, D., Redman, T., \& Maguire, S. (2008). Green HRM: A review, process model, and research agenda. University of Sheffield Management School Discussion Paper, 1, 1-46.

Rothenberg, S. (2003). Knowledge content and worker participation in environmental management at NUMMI. Journal of Management Studies, 40, 1783-1802.

Tranfield, D., Denyer, D., \& Smart, P. (2003). Towards a methodology for developing evidence-informed management knowledge by means of systematic review. British journal of management, 14(3), 207-222.

Wehrmeyer, W. (1996). Green policies can help to bear fruit. People Management, 38-42.

Zoogah, D. B. (2011). The dynamics of Green HRM behaviors: A cognitive social information processing approach. German Journal of Human Resource Management, 25(2), 117139.

\section{Copyrights}

Copyright for this article is retained by the author(s), with first publication rights granted to the journal. This is an open-access article distributed under the terms and conditions of the Creative Commons Attribution license (http://creativecommons.org/licenses/by/4.0/) 